\title{
A preliminary assessment of the differences between the Malaysian and Bangladesh strains of the highly lethal Nipah virus
}

Proyasha Roy ${ }^{a}$, Sumanta Dey ${ }^{a}$, Tathagata Dutta ${ }^{a}$, Ashesh Nandy ${ }^{a}$ and Subhas C Basak

${ }^{a}$ Centre for Interdisciplinary Research and Education, 404B Jodhpur Park, Kolkata 700058, India

${ }^{b}$ Department of Chemistry and Biochemistry, University of Minnesota Duluth, 1802 Stanford Avenue, Duluth, MN 5581, USA

\begin{tabular}{|l|l|l|}
\hline Graphical Abstract & $\begin{array}{l}\text { Abstract. } \\
\text { The recent emergence of a highly lethal zoonotic } \\
\text { virus, the Nipah virus, has raised concerns of a } \\
\text { possible pandemic with high fatality ratios. While } \\
\text { the similarities of the Malaysian and Bangladesh } \\
\text { strains of the virus have been commented upon by } \\
\text { various authors, the significant differences, if any, } \\
\text { between the two strains that have led to starkly } \\
\text { different fatality ratios of } 40 \% \text { and } 75 \text {-100\%, } \\
\text { respectively, have not been satisfactorily } \\
\text { addressed. In this report, we submit the results of } \\
\text { our preliminary study of the strains as available } \\
\text { from their complete genomes and show that the two } \\
\text { strains are indeed different and should form part of } \\
\text { a focused surveillance program. }\end{array}$ \\
\hline
\end{tabular}

\section{Introduction}

A recent zoonotic disease of great public health concern, the Nipah virus, has affected mainly in the South-East Asia region with a fatality rate estimated to be between 40 and 75\% [1]. The first Nipah infection was recognized in 1998-1999 during an outbreak among pig farmers in Malaysia and Singapore [2]. Nipah was first reported in India and Bangladesh in 2001. Since then, nearly every year outbreaks have occurred in Bangladesh and has been identified periodically in eastern India [3]. As of 28 May, this year, 13 deaths have been reported from an epidemic in Kerala, a state in southern India [4].

However, as the virus spread from Malaysia to Bangladesh, the lethality of the virus appeared to change. The case fatality ratio (CFR) was about $40 \%$ in Malaysia, but it increased to $75 \%-100 \%$ in Bangladesh 
[1. This implies that there were definite modifications in the viral genome that circulated in Malaysia from the virus circulating in Bangladesh or India. Moreover, reports of human-to-human transmission of the Nipah virus among the residents in the affected areas of Bangladesh causes a heightened worry about a pandemic spread of a lethal disease [5]. Although many authors have concentrated upon the similarities between the Malaysian and Bangladeshi strains of the Nipah virus [6], it is important to understand and characterize Nipah virus from Malaysia and Bangladesh/India to determine what may be the significant differences in their infectivity.

We report here the phylogenetic analysis of the viral genomes which clearly shows two distinct clades: one from Malaysia and another from India and Bangladesh, implying that certain characteristic differences exist between the two groups. We also show the perceptible differences in the graphical representations of the fusion and the glycoprotein genes of the two strains. These preliminary results indicate the need for more focused surveillance to monitor the changes in and the further spread of the Nipah virus.

\section{Materials and Methods}

From the data on Nipah virus in the National Center for Biotechnology Information (NCBI), 12 complete genomes were available for this work. Phylogenetic analysis was carried out using MEGA 7.0 (Molecular Evolutionary Genetics Analysis) for the fusion and glycoprotein genes for the Nipah Bangladesh (NiV-BD) set and Nipah Malaysia (NiV-ML) set. Fusion and glycoprotein genes were selected since they are surface exposed and important for viral attachment to the host cell and are therefore ideal candidates for vaccine design. For comparison of the genes, the Nandy 2D graphical representation method was employed [7] and numerically characterized using the graph radius ( $g_{R}$ ) descriptor [8].

\section{Results and Discussion}

Phylogenetic analysis for the whole genomes of the 12 Nipah sequences shows two distinct clusters, one belonging to the Malaysia strain and the other to the Bangladesh strain, with one sub-sub-clade under Bangladesh representing the sequence isolated from India (Fig. 1). Of the 12 sequences, 2 of them, accession numbers NC_002728 and AF212302, were not annotated but clustered in the Malaysian group and were taken as such for this paper.

Although NiV-ML and NiV-BD strains are placed in different clades in the phylogenetic tree, there are close resemblances in their nucleotide distributions as visualized in the 2D graphical representation scheme. The plots of the base distributions in the fusion and glycoprotein surface genes (Figs. 2a and 


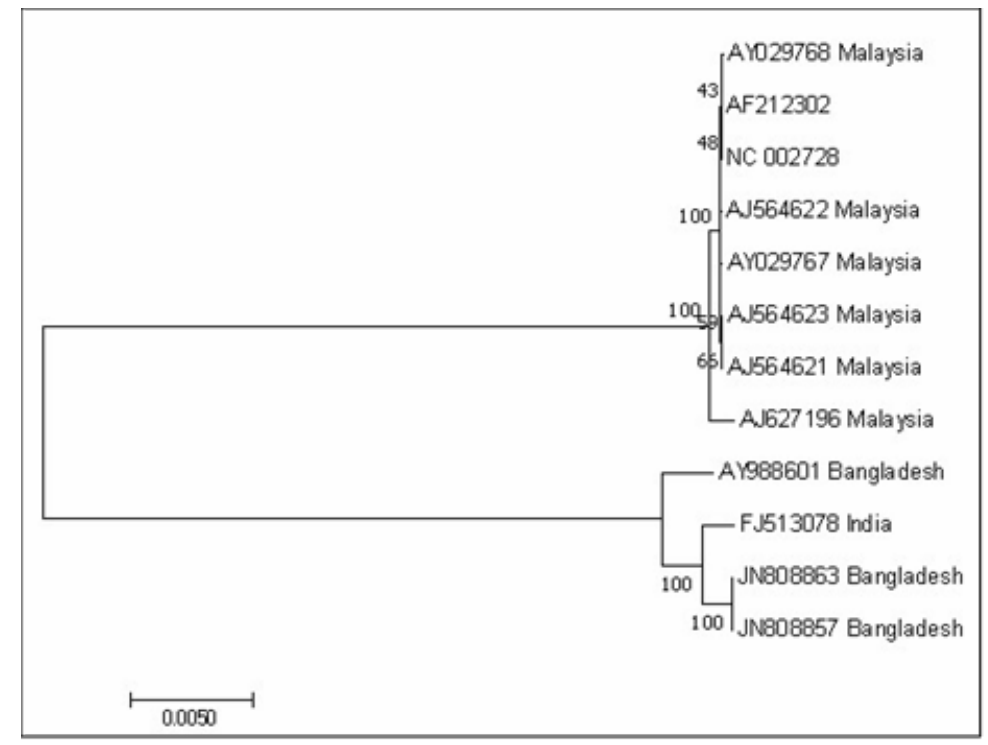

Figure 1. Phylogenetic tree of 12 whole genome sequences of NiV.

2b), and the values of the graph radii $g_{R}$ (Table 1) display the similarity between the distributions in NiV-ML and NiV-BD strains. Similar results were found in case of the other genes (nucleocapsid N, phosphoprotein P, matrix M, and large polymerase $\mathrm{L}$ ) and in the whole genomes. This is not unexpected as a BLAST analysis of the entire genomes show an identity of $92 \%$ at $100 \%$ query coverage.

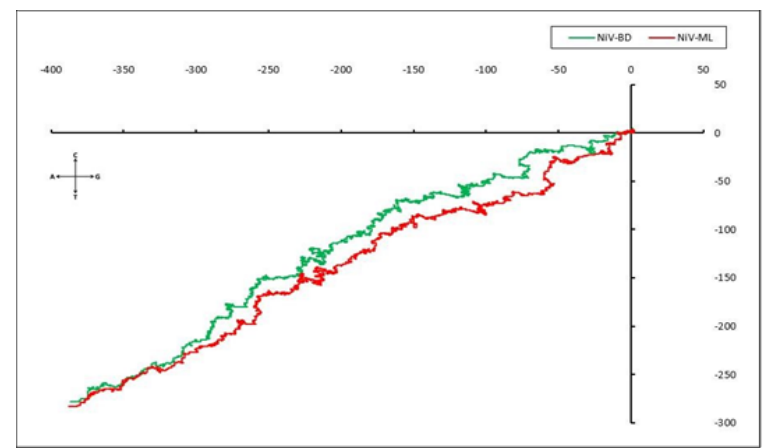

Figure 2a. Plot of fusion gene of NiV-BD (AY988601) and NiV-ML (AF212302). ACGT axes system

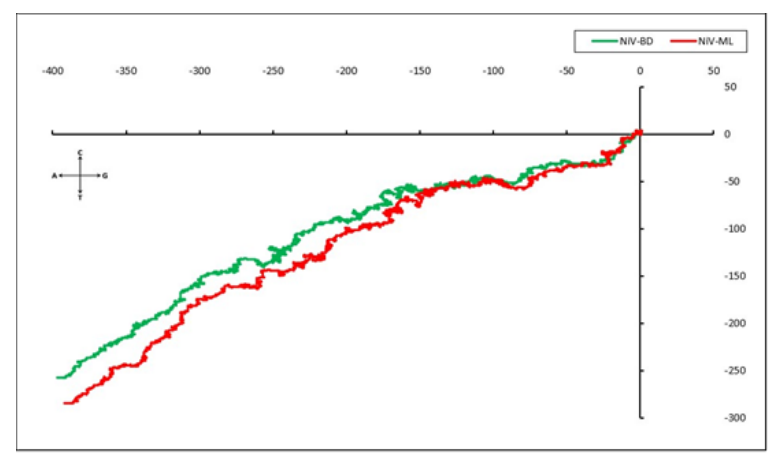

Figure 2b. plot of glycoprotein gene of NiV-BD (AY988601) and NiV-ML (AF212302). ACGT axes system.

Table 1. $g_{\mathrm{R}}$ values for whole genomes, fusion and glycoprotein genes of $12 \mathrm{NiV}$ sequences.

\begin{tabular}{|c|c|c|c|c|}
\hline \multirow{2}{*}{ Accession No. } & \multirow{2}{*}{ Strain } & \multicolumn{3}{|c|}{ gR values } \\
\cline { 3 - 5 } & & Whole genome & Fusion & Glycoprotein \\
\cline { 3 - 5 } & & 1382.57 & 140.06 & 134.73 \\
\hline FJ513078 & NiV-BD & 1394.55 & 138.16 & 136.42 \\
\hline AY988601 & NiV-BD & 1375.35 & 140.45 & 135.23 \\
\hline JN808857 & NiV-BD & 1375.35 & 140.45 & 135.23 \\
\hline JN808863 & NiV-BD & 1407.22 & 148.16 & 137.14 \\
\hline AF212302 & NiV-ML & 1408.78 & 148.63 & 138.53 \\
\hline AJ564621 & NiV-ML & 1407.46 & 148.16 & 137.14 \\
\hline AJ564622 & NiV-ML & 1408.26 & 148.16 & 138.53 \\
\hline AJ564623 & NiV-ML & 1405.77 & 151.36 & 136.93 \\
\hline AJ627196 & NiV-ML & 1408.29 & 148.16 & 137.14 \\
\hline AY029767 & NiV-ML & 1407.97 & 148.16 & 137.14 \\
\hline AY029768 & NiV-ML & 1407.22 & 148.16 & 137.14 \\
\hline NC_002728 & NiV-ML & & & \\
\hline
\end{tabular}


Since the values of the graph radii are not very different for the NiV-ML and NiV-BD strains, we performed an ANOVA analysis to determine whether the apparent differences in the $\mathrm{g}_{\mathrm{R}}$ of the two strains of the virus are indeed significant. The results of the ANOVA analysis clearly rejected the null hypothesis: For the fusion protein. the F-value evaluated to $168.31\left(F_{\text {critical }}=4.96\right)$, while for the glycoprotein genes the F- value was $24.41\left(F_{\text {critical }}=4.96\right)$, both of which had an effective p-value $<0.05$. Thus, the small differences in the apparent visual similarity of the two strains in terms of the 2D graphical representations are seen to be significant and forms the basis for the two distinct clades in the phylogenetic tree.

Analyses of other properties characterizing the genomes of the two strains are in progress and will be reported in due course.

\section{Conclusions}

Our study has clearly shown that significant differences exist between the genomes of Nipah virus from Bangladesh and Malaysian strains. These results indicate that the base composition and distribution characteristics of two strains of the Nipah virus are significantly different and perhaps constitute the cause of the differences in the infectivity and pathogenicity seen between the NiV-ML and NiV-BD strains. Other analyses of codon usage, etc. are being undertaken to further determine more fundamental and significant differences, if any, to highlight the need for focused surveillance of an emergent deadly virus.

\section{References}

1. WHO, Disease outbreak news 31 May 2018. http://www.who.int/csr/don/31-may-2018-nipahvirus-india/en/ (Accessed 15 November, 2018)

2. Chua KB; Bellini WJ; Rota PA; Harcourt BH; Tamin A; Lam SK; Ksiazek TG; Rollin PE; Zaki SR; Shieh W; Goldsmith CS; Gubler DJ; Roehrig JT; Eaton B; Gould AR; Olson J; Field H; Daniels P; Ling AE; Peters CJ; Anderson LJ; Mahy BW. Nipah virus: a recently emergent deadly paramyxovirus. Science 2000, 288(5470), 1432-5.

3. Islam MS; Sazzad HMS; Satter SM; Sultana S; Hossain MJ; Hasan M; et al. Nipah Virus Transmission from Bats to Humans Associated with Drinking Traditional Liquor Made from Date Palm Sap, Bangladesh, 2011-2014. Emer Infec Dis. 2000, 22(4), 664-670.

4. Chatterjee P. Nipah virus outbreak in India. The Lancet 2018, 391(2200).

5. Escaffre O; Borisevich V; Vergara LA; Wen JW; Long D; Rockx B. Characterization of Nipah virus infection in a model of human airway epithelial cells cultured at an air-liquid interface. $J$ Gen Virol. 2016, 97, 1077-1086.

6. Lo MK; Peeples ME; Bellini WJ; Nichol ST; Rota PA; et al. Distinct and Overlapping Roles of Nipah Virus P Gene Products in Modulating the Human Endothelial Cell Antiviral Response. PLOS ONE 2012, 7(10), 47790.

7. Nandy, A. A New Graphical Representation and Analysis of DNA Sequence Structure. Current Science 1994, 66, 309-314. 
8. Raychaudhury C; Nandy A. Indexing Scheme and Similarity Measures for Macromolecular Sequences. J Chem Inf Comput Sci. 1999, 39, 243-247. 